\title{
Corrosion Inhibitive Evaluation of an Environmentally Friendly Water-Base Acrylic Terpolymer on Mild Steel in Hydrochloric Acid Media
}

\author{
MOJTABA VAKILI AZGHANDI, ALI DAVOODI, GHOLAM ALI FARZI, \\ and ALI KOSARI
}

The corrosion inhibitive performance of an environmentally friendly water-base acrylic terpolymer [methyl methacrylate/Butyl Acrylate/Acrylic acid (ATP)] on mild steel in $1 \mathrm{M} \mathrm{HCl}$ was investigated by alternating current and direct current electrochemical techniques and the quantum chemical method. An efficiency of more than 97 pct was obtained with $0.8 \mathrm{mmol} / \mathrm{L}$ ATP. The increase in inhibitor concentration and immersion time has a positive effect, while the temperature influence is negligible on the inhibitor efficiency. The present terpolymer obeys the Langmuir isotherm, and thermodynamic calculation reveals a chemisorption type on the surface. Density functional calculations showed that the lone pairs of electrons of oxygen in the structure of three monomers are suitable sites to adsorb onto the metal surface. Finally, in the presence of ATP, a decrease in surface roughness and corrosion attacks was demonstrated by atomic force microscopy and optical microscopy examinations, respectively.

DOI: $10.1007 / \mathrm{s} 11661-013-1904-7$

(c) The Minerals, Metals \& Materials Society and ASM International 2013

\section{INTRODUCTION}

MANY industrial sections such as the acid cleaning bath, the water cooling system, various refinery units, pipelines, chemical operations, steam generators, ballast tanks, oil, and gas production units are involved with inhibitors due to high corrosion rates in these parts. ${ }^{[1-6]}$ Recently, the use of polymers as corrosion inhibitors has attracted considerable attention because of their inherent stability and cost effectiveness. ${ }^{[7-11]}$ Owning to multiple adsorption sites, the polymeric compounds adsorb more strongly on the metal surface in comparison with their monomer analogues. In addition, they can form complexes with metal ions on the metal surface; therefore, it is expected that the polymers will act as appropriate corrosion inhibitors. ${ }^{[10,12-14]}$ Also, it has been reported that the toxicity of polymers is less than their monomer analogs. ${ }^{[14-16]}$

Generally, various types of polymers, which are employed as corrosion inhibitors, can be classified into two groups: (1) synthetic polymers such as polyvinyl alcohol, polyethylene glycol, polyacrylic acid, polyacrylamide, polyaniline derivatives, and polyvinyl pyrollidone, ${ }^{[13,17-21]}$ and (2) natural polymers such as saccharides, plant extracts, and natural honey. ${ }^{[22-25]}$

MOJTABA VAKILI AZGHANDI, Master of Science Student, ALI DAVOODI, Associate Professor, and GHOLAM ALI FARZI, Assistant Professor, are with the Materials and Polymers Engineering Department, Hakim Sabzevari University, Sabzevar 391, Iran. Contact e-mail: adavoodi@kth.se ALI KOSARI, Master of Science Student, is with the Materials and Metallurgical Engineering Department, Faculty of Engineering, Ferdowsi University of Mashhad, Mashhad 917751111, Iran.

Manuscript submitted June 20, 2012.

Article published online August 21, 2013
Since most of the polymeric inhibitors are insoluble in aqueous solutions, it is common to solve them in an organic solvent before adding them in corrosive environments. This process is subject to an environmental issue, and consequently numerous attempts were made to replace it by more environmentally friendly methods. ${ }^{[11,16,22]}$ In this perspective, water-base acrylic polymers having functional groups of $\mathrm{OH}$ and $\mathrm{COOH}$ are being mentioned as corrosion inhibitors in different corrosive media. This type of polymer does not need to solve in organic solvent, and most of them are environmentally friendly compounds. ${ }^{[1,26]}$ The increase in hydrocarbon chain length in polymers decreases their solubility. On the other hand, the presence of hydrophilic functional groups $\left(\mathrm{OH}, \mathrm{COOH}\right.$, and $\left.\mathrm{NH}_{2}\right)$ increases their solubility. As a result of less solubility and emulsification characteristics, the aforementioned copolymers do not need to solve in an organic solvent. ${ }^{[1]}$ Also, it has been reported that water-base acrylic polymers have more stability and inhibitive behavior than other copolymers and polymers such as acrylic. ${ }^{[1,27,28]}$ Several researchers introduced some water-soluble polymers as inhibitors for iron and cadmium. ${ }^{[11,29]}$ They found that the hydroxyl group of polyvinyl alcohol and polyethylene glycol can make a bridge between the polymer and the surface of the electrode, resulting in an inhibitive effect in the $\mathrm{HCl}$ solution. The inhibitive influence of these polymers is structurally related to the cyclic rings, heteroatom (oxygen and nitrogen), which are the major active cites for adsorption onto the metal surface. ${ }^{[13,21,23,30]}$

The aim of the present work is to investigate the effect of a water-base terpolymer from the acrylic group on the corrosion behavior of mild steel in $1 \mathrm{M} \mathrm{HCl}$. In a previous work, the present compound was examined as 
a corrosion inhibitor for mild steel in petroleum solution in both static and hydrodynamic conditions. ${ }^{[11]}$ The authors believe that the present acrylic terpolymer is capable of decreasing the mild steel corrosion rate in other corrosive media such as $\mathrm{HCl}$. Consequently, the present work was conducted to explore the effect of various conditions, including inhibitor concentration, temperature, and immersion time, on the inhibitive behavior of the present compound in the stagnant condition using electrochemical techniques and the quantum chemical method. In addition, the corrosion attack morphology of the mirrorlike polished mild steel in $1 \mathrm{M} \mathrm{HCl}$ in the absence and presence of inhibitor was investigated through atomic force microscopy (AFM) and optical microscopy (OM) techniques. Finally, it should be mentioned that this water-base copolymer has been used in adhesive commercial resin in the coating industry, ${ }^{[26,31]}$ and until now, no study has been carried out on the inhibitive performance of this compound as a corrosion inhibitor in acidic media.

\section{EXPERIMENTAL}

\section{A. Poly (Methyl Methacrylate/Butyl Acrylate/Acrylic Acid)}

In this work, the corrosion inhibitor was selected to be a water-base acrylic copolymer, which is a terpolymer of methyl methacrylate/Butyl Acrylate/Acrylic acid (ATP) with 49/49/2 wt pct ratio. ATP has been synthetized by the conventional emulsion polymerization. During synthetizing, the polymerization was carried out at $343 \mathrm{~K}\left(70{ }^{\circ} \mathrm{C}\right)$ for 4 hours. The polymer was obtained in the form of emulsified phase approximately $50 \mathrm{wt}$ pet in water. The obtained acrylic emulsion polymer contains the colloidal dispersion of polymer particles in water. It should be mentioned that ATP is miscible in any ratio with water; however, polymer particles are in a dispersed form (and not soluble) in water. Subsequently, ATP was characterized by a particle size analyzer using the dynamic light scattering (DLS) technique. The average particle size and also the molecular weight of ATP were approximately $160 \mathrm{~nm}$ and $10^{5} \mathrm{~g} / \mathrm{mol}$, respectively. In addition, the Tg of ATP was measured to be about $293 \mathrm{~K}\left(20^{\circ} \mathrm{C}\right)$. The molecular structures of three monomers, which construct the present terpolymer, are presented in Figure 1.

\section{B. Specimen and Corrosive Media}

The corrosion test specimen (working electrode) was selected from a mild steel rod with the following chemical composition (wt pet): 0.17 pet C, 0.3 pet Si, 0.4 pct $\mathrm{Mn}, 0.05$ pct S, 0.05 pct $\mathrm{P}$, and Fe balance. The sample was then mounted in a self-cure epoxy resin resulting in $0.785 \mathrm{~cm}^{2}$ exposed area. Before each test, the specimen was ground down to 1200 grit emery paper, then washed with ethanol and dried with warm air. The electrolyte solution in all experiments was $1 \mathrm{M}$ $\mathrm{HCl}$ prepared by Merck reagent and deionized water. Also, the inhibited solutions were prepared with direct

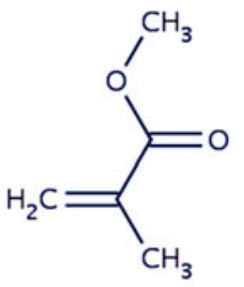

(a)

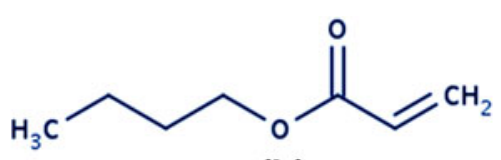

(b)

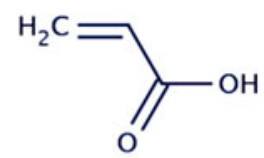

(c)
Fig. 1-Molecular structures of (a) methyl methacrylate, (b) butyl acrylate, and (c) acrylic acid.

addition of various concentrations of ATP, which was in emulsion form in $1 \mathrm{M} \mathrm{HCl}$. To control the cell temperature at constant condition while running the experiments, a water bath with accuracy within $\pm 1{ }^{\circ} \mathrm{C}$ was employed.

\section{Electrochemical Measurements}

The electrochemical measurements were carried out in a conventional three-electrode cell in which the working electrode was the described mild steel sample, and the saturated calomel electrode (SCE) and a platinum wire were the reference and counter electrode, respectively. An IVIUM Potentiostat (Ivium Technologies, Eindhoven, The Netherlands) was employed to perform all electrochemical measurements.

In order to reach a steady state, the working electrode was immersed in the prepared solution for 30 minutes. To measure linear polarization resistance (LPR), the potential of the electrode was perturbed from -15 to $+15 \mathrm{mV}$ around the corrosion potential with $0.5 \mathrm{mV} / \mathrm{s}$ scan rate. Also, potentiodynamic polarization was carried out with a constant sweep rate of $1 \mathrm{mV} / \mathrm{s}$ in the range of -300 to $+300 \mathrm{mV}$ with respect to corrosion potential. The electrochemical impedance spectroscopy (EIS) measurement was performed using AC signals with $10 \mathrm{mV}$ amplitude in the frequency range $100 \mathrm{kHz}$ to $0.01 \mathrm{~Hz}$ at corrosion potential. EIS Analyzer software was used to fit the experimental results of EIS measurements using the appropriate equivalent circuit. It should be noted that all electrochemical experiments were performed in a condition in which the solutions were open to air at stagnant condition.

The effect of the inhibitor concentration of acrylic terpolymer on the mild steel corrosion rate in $1 \mathrm{M} \mathrm{HCl}$ solution at $298 \mathrm{~K}\left(25{ }^{\circ} \mathrm{C}\right)$ was studied by potentiodynamic polarization, EIS, and LPR methods. In this way, the concentrations of $0.1,0.2,0.4,0.6$, and $0.8 \mathrm{mmol} / \mathrm{L}$ (ppm) were selected. The temperature influence on the mild steel corrosion rate was explored in the absence and presence of $0.8 \mathrm{mmol} / \mathrm{L} \mathrm{ATP}$ in $1 \mathrm{M} \mathrm{HCl}$ in the range of $298 \mathrm{~K}, 303 \mathrm{~K}, 308 \mathrm{~K}$, and $313 \mathrm{~K}\left(25^{\circ} \mathrm{C}, 30{ }^{\circ} \mathrm{C}, 35^{\circ} \mathrm{C}\right.$, and $40{ }^{\circ} \mathrm{C}$ ) using the potentiodynamic polarization technique. Also, to investigate the effect of immersion time on inhibitor performance, potentiodynamic polarization and EIS measurements were run at $1,6,12,18$, and 24 hours after immersion in a solution 
containing $1 \mathrm{M} \mathrm{HCl}$ in the presence of $0.8 \mathrm{ppm} \mathrm{ATP} \mathrm{at}$ $298 \mathrm{~K}\left(25^{\circ} \mathrm{C}\right)$.

\section{Corrosion Attack Morphology Investigation}

\section{Optical microscope}

Optical microscopy was accomplished in order to investigate corrosion attack morphology in the absence and presence of inhibitor. The surface of specimens was mechanically polished down to $0.05-\mu \mathrm{m}$ alumina slurry until a mirrorlike surface was acquired. Subsequently, the specimens were immersed in $1 \mathrm{M} \mathrm{HCl}$ in the absence and presence of $0.8 \mathrm{mmol} / \mathrm{L}$ for 90 minutes at room temperature in stagnant condition. After bringing out each specimen, it was washed and cleaned by ethanol and immediately dried with warm air.

\section{Atomic force microscope}

AFM is a powerful technique that can be used to investigative the surface morphology at nano- to microscale, and recently, it has been a new choice to study the influence of inhibitors on the generation and the progress of the corrosion at the metal/solution interface. ${ }^{[32]}$ In this work, the sample was selected from a mild steel rod with $1-\mathrm{cm}$ diameter and was abraded with emery paper (grade 320-500-800); then, a mirrorlike surface was provided by $0.05-\mu \mathrm{m}$ alumina slurry. Finally, the specimen surface was washed with distilled water and acetone. After immersion in $1 \mathrm{M} \mathrm{HCl}$ without and with addition of $0.8 \mathrm{mmol} / \mathrm{L}$ ATP in stagnant condition at $298 \mathrm{~K}\left(25{ }^{\circ} \mathrm{C}\right)$ for 90 minutes, the sample was cleaned with distilled water and immediately dried with a warm air blow. Subsequently, the corrosion attack topographies of specimens were characterized by AFM in noncontact scanning mode.

\section{E. Quantum Chemical Study}

In order to investigate the effect of molecular structures of monomers, quantum chemical study was carried out. The optimized structure and the highest occupied molecular orbital (HOMO) of three monomers were geometrically calculated by electron density function theory (DFT) using a B3LYP level and $3-21 \mathrm{G}^{* *}$ basis set with Gaussian 98 software (Gaussian, Inc., Wallingford, CT).

\section{RESULTS AND DISCUSSION}

\section{A. Effect of Inhibitor Concentration}

\section{Potentiodynamic polarization}

The polarization curves are depicted in Figure 2, and the electrochemical parameters including corrosion potential $\left(E_{\text {corr }}\right)$, corrosion current density $\left(i_{\text {corr }}\right)$, and cathodic and anodic Tafel slopes $\left(\beta_{a}\right.$ and $\left.\beta_{c}\right)$ obtained by the extrapolation of Tafel slopes are presented in Table I. Also, the values of surface coverage $(\theta)$ and inhibition efficiency are calculated using the following equation ${ }^{[33]}$ :

$$
\theta=\frac{i_{\text {corr }}^{0}-i_{\text {corr }}}{i_{\text {corr }}^{0}}
$$

$$
\eta=\theta \times 100
$$

where $\left(i_{\text {corr }}^{0}\right)$ and $\left(i_{\text {corr }}\right)$ represent the corrosion current densities in the absence and presence of the inhibitor, respectively.

Figure 2 indicates that the present terpolymer is capable of significantly decreasing both anodic and cathodic current densities. Also, Table I shows that the inhibitor concentration has a positive effect on inhibitive behavior of ATP so that the efficiency values considerably increase with the increase in terpolymer concentration (i.e., 89.8 pct in $0.1 \mathrm{mmol} / \mathrm{L}$ to 95 pct in $0.8 \mathrm{mmol} / \mathrm{L}$ ). It is believed that the long chains of the present terpolymer adsorb onto the metal surface and, consequently, slow the metal dissolution and hydrogen evolution by blocking many available active sites. Although the presence of defects on the organic layer created by inhibitor adsorption cannot be ruled out, hydrogen evolution and metal dissolution may occur from these regions where there is no inhibitor coverage (i.e., $1-\theta$ ). ${ }^{[2]}$ In addition, Figure 2 reveals that an increase in ATP concentration causes a decrease in both anodic and cathodic current densities so that this decrease is more pronounced in the case of cathodic branches. Moreover, it can be claimed that in higher concentrations of the inhibitor, the present terpolymer has a tendency to block more of the cathodic sites, which act as suitable sites for hydrogen evolution, in comparison with anodic sites, which are appropriate places for anodic dissolution. ${ }^{[34-36]}$

Table I reveals that in the presence of inhibitor, the values of anodic and cathodic Tafel slopes $\left(\beta_{a}\right.$ and $\left.\beta_{c}\right)$ are significantly diminished and also that the corrosion potential slightly shifted toward more negative values. The variation of Tafel slopes refers to a change in reaction kinetics. This can be explained by the fact that with anodic and cathodic polarizing of the sample, the reaction kinetics speed up in the inhibited solution in comparison with the uninhibited one, producing a

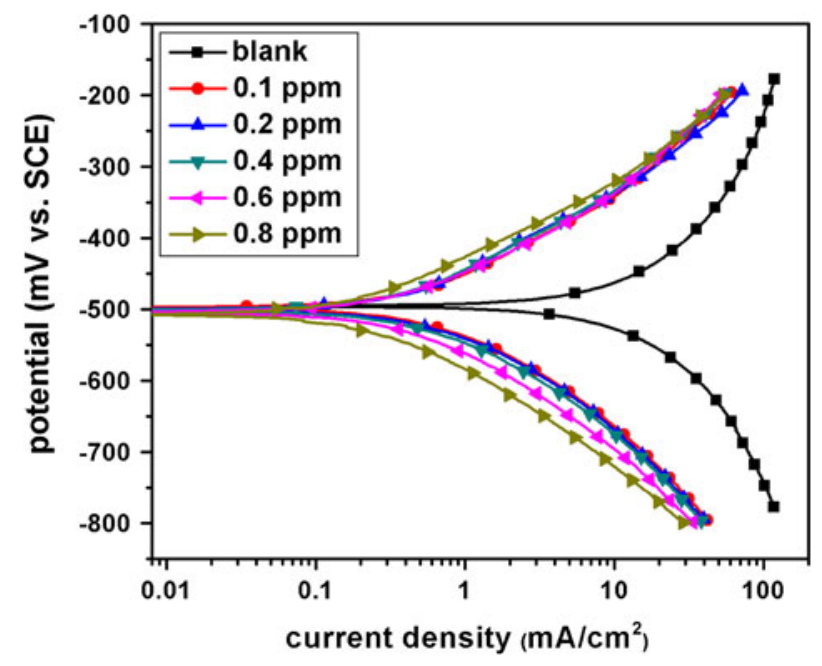

Fig. 2-Potentiodynamic polarization curves of inhibitor in different concentrations at $298 \mathrm{~K}\left(25^{\circ} \mathrm{C}\right)$. 
Table I. Potentiodynamic Polarization Parameters of Mild Steel in 1 M HCl Solution in the Absence and Presence of Various Concentrations of ATP at $298 \mathrm{~K}\left(25^{\circ} \mathrm{C}\right)$

\begin{tabular}{|c|c|c|c|c|c|c|}
\hline $\begin{array}{l}\text { Concentration } \\
(\mathrm{mmol} / \mathrm{L})\end{array}$ & $E_{\text {corr }}(\mathrm{mV} v s \mathrm{SCE})$ & $i_{\text {corr }}\left(\mathrm{mA} / \mathrm{cm}^{2}\right)$ & $\beta_{a}(\mathrm{mV} /$ Decade $)$ & $\beta_{c}(\mathrm{mV} /$ Decade $)$ & $\theta$ & $\eta(\mathrm{Pct})$ \\
\hline Blank & -478 & 1.398 & 240 & 228 & - & - \\
\hline 0.1 & -496 & 0.142 & 136 & 150 & 0.898 & 89.8 \\
\hline 0.2 & -494 & 0.130 & 120 & 157 & 0.907 & 90.7 \\
\hline 0.4 & -497 & 0.102 & 126 & 137 & 0.927 & 92.7 \\
\hline 0.6 & -498 & 0.092 & 119 & 137 & 0.935 & 93.5 \\
\hline 0.8 & -500 & 0.071 & 121 & 143 & 0.950 & 95.0 \\
\hline
\end{tabular}

negative effect of the present terpolymer on the corrosion rate of mild steel. However, the considerable decrease in active area is the main reason for diminishing the net corrosion current density in inhibited solution. ${ }^{[37]}$ Considering that the present terpolymer decreases both anodic and cathodic current densities while it has no effect on corrosion potential, this compound can be classified as a mixed-type inhibitor.

\section{Electrochemical impedance spectroscopy}

EIS is a valuable method that has been widely used to study the inhibitive behavior of many compounds. ${ }^{[2]} \mathrm{It}$ provides information on both the resistive and capacitive behavior at the interface and makes it possible to assess the performance of the tested compounds as inhibitors for metals. ${ }^{[38]}$ Here the effect of inhibitor concentration on inhibitive behavior of the present terpolymer on mild steel in $1 \mathrm{M} \mathrm{HCl}$ was investigated using EIS measurement after 1 hour immersion time at $298 \mathrm{~K}\left(25^{\circ} \mathrm{C}\right)$. Figure 3 depicts Nyquist plots in the absence and presence of different inhibitor concentrations. As seen, Nyquist plots consist of a depressed semicircle in inhibited and uninhibited solutions. This capacitive loop is attributed to the double-layer capacitance in parallel with the charge transfer resistance. In addition, Figure 3 shows that a rise in terpolymer concentration results in an increase in the semicircle diameter, indicating the inhibition of the corrosion process. ${ }^{[39-41]}$

The impedance parameters were obtained by EIS analyzer software using an appropriate equivalent circuit (Figure 3) for the metal-electrolyte interface and are presented in Table II. Also, inhibitor efficiency was calculated by the charge transfer resistance via the following formula ${ }^{[36]}$ :

$$
\text { pct } \eta=\frac{R-R^{\circ}}{R} \times 100
$$

where $R^{\circ}$ and $R$ are the charge transfer resistance of mild steel in the absence and presence of inhibitor, respectively. In addition, the values of double-layer capacitance were calculated by Eq. $[4]^{[34]}$.

$$
C_{d l}=P^{1 / n} R_{c t}^{(1-n) / n}
$$

In the preceding expressions, $P, n$, and $R_{c t}$ are the magnitude of the constant phase element (CPE), the deviation parameter, and the charge transfer resistance

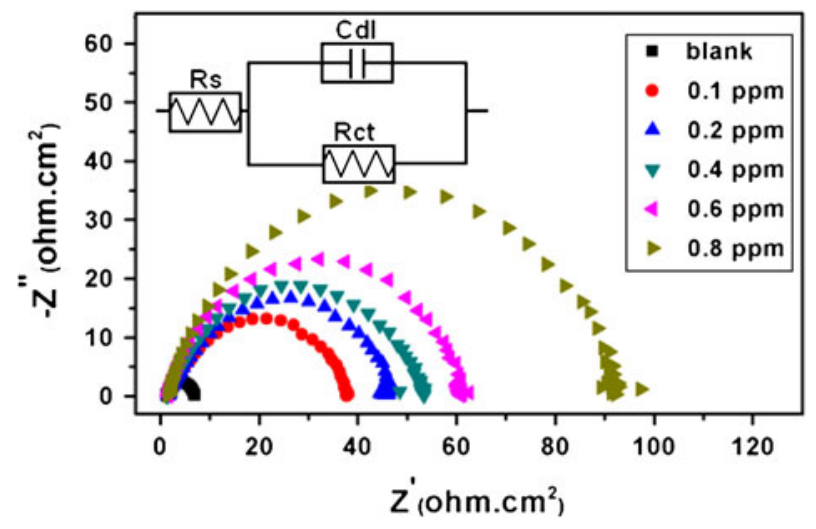

Fig. 3-Results of EIS as Nyquist plot in various concentrations at $298 \mathrm{~K}\left(25^{\circ} \mathrm{C}\right)$ and equivalent circuit.

of mild steel, respectively. As known, the CPE element is a nonideal capacitance that is generally used to simulate experimental data. ${ }^{[2,18]}$ Deviations from the ideal semicircle can be due partly to the surface inhomogeneities and mass transport processes. Thus, in these situations, pure double layer capacitors are better described by a transfer function with CPE. ${ }^{[36,42,43]}$

Evaluation of the results in Table II revealed that with an increase in ATP concentration, the values of $R_{c t}$ increase while the double layer capacitance values decrease. An increase in $R_{c t}$ refers to a greater block of the active area at the metal surface as a result of increasing inhibitor concentration. Also, the decrease in double-layer capacitance indicates that in the presence of various inhibitor concentrations, a protective layer is created onto the surface, since the double layer between the charged metal surface and the solution is considered as an electrical capacitor. In addition, the values of $n$ show an increase with increasing inhibitor concentration. This can be attributed to the decrease in surface roughness and the slight improvement of surface homogeneity due to inhibitor adsorption on the most active sites. ${ }^{[2,18,44]}$

The terpolymer adsorption on the iron surface decreases its electrical capacity due to displacement of the water molecules and other ions that are originally adsorbed on the surface with inhibitor molecules. According to the Helmholtz model, double-layer capacitance is related to structural parameters as follows ${ }^{44]}$.

$$
C_{d l}=\frac{\varepsilon_{0} \varepsilon}{d} S
$$


Table II. EIS Parameters of Mild Steel Electrode in $1 \mathrm{M} \mathrm{HCl}$ Solution in the Absence and Presence of Various Concentrations of ATP at $298 \mathrm{~K}\left(25^{\circ} \mathrm{C}\right)$

\begin{tabular}{|c|c|c|c|c|c|c|c|c|}
\hline \multirow{2}{*}{$\begin{array}{l}\text { Concentration } \\
(\mathrm{mmol} / \mathrm{L})\end{array}$} & \multicolumn{6}{|c|}{ EIS } & \multicolumn{2}{|c|}{ LPR } \\
\hline & $R_{s}\left(\Omega \cdot \mathrm{cm}^{2}\right)$ & $R_{c t}\left(\Omega \cdot \mathrm{cm}^{2}\right)$ & $P\left(\mu \mathrm{F} / \mathrm{cm}^{2}\right)$ & $n$ & $C_{d l}\left(\mu \mathrm{F} / \mathrm{cm}^{2}\right)$ & $\eta(\mathrm{Pct})$ & $R_{p}\left(\Omega \cdot \mathrm{cm}^{2}\right)$ & $\eta(\mathrm{Pct})$ \\
\hline Blank & 1.3 & 5.7 & 1071 & 0.78 & 270 & - & 4 & - \\
\hline 0.1 & 1.9 & 36.5 & 401 & 0.79 & 125 & 91.6 & 50 & 91.8 \\
\hline 0.2 & 1.9 & 45.5 & 309 & 0.79 & 121 & 93.2 & 60 & 93.1 \\
\hline 0.4 & 1.6 & 51.7 & 296 & 0.83 & 125 & 94.0 & 70 & 94.1 \\
\hline 0.6 & 1.6 & 60.0 & 175 & 0.83 & 66 & '94.9 & 80 & 94.9 \\
\hline 0.8 & 1.6 & 91.0 & 103 & 0.89 & 57 & 96.6 & 121 & 96.6 \\
\hline
\end{tabular}

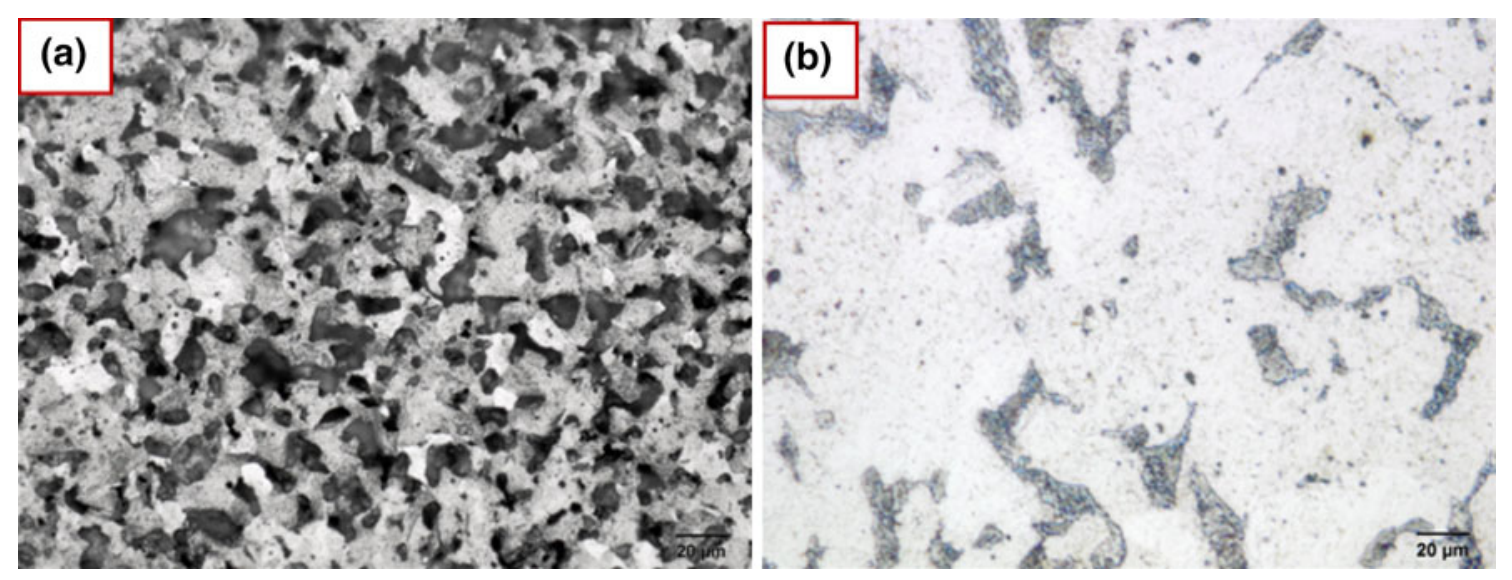

Fig. 4 Corrosion attack morphology obtained by optical microscope (a) blank solution and $(b)$ in the presence of $0.8 \mathrm{mmol} / \mathrm{L}$ ATP.

where $d$ is the thickness of the film, $S$ is the surface area of the electrode, $\varepsilon_{0}$ is the permittivity of the air, and $\varepsilon$ is the local dielectric constant. The decrease in $C_{d l}$ is probably due to a decrease in the local dielectric constant or an increase in the thickness of a protective layer at the electrode surface in the presence of an inhibitor. ${ }^{[45]}$ An increase in inhibitor concentration, and a decrease in the surface area, which acts as a place for surface charging, may be another reason for the decrease in $C_{d l} \cdot{ }^{[46]}$

It should be mentioned that the efficiency values calculated by EIS results in the absence and presence of different concentrations of investigated terpolymer are in close correlation with those of polarization discussed in Section 1. In addition, EIS measurement confirms that this compound has a good inhibitive behavior for mild steel in $\mathrm{HCl}$ media.

\section{Linear polarization resistance}

The effect of inhibitor concentration on corrosion behavior of mild steel in $1 \mathrm{M} \mathrm{HCl}$ solution at $298 \mathrm{~K}$ $\left(25^{\circ} \mathrm{C}\right)$ was studied by the linear polarization resistance (LPR) method, which is a useful and fast method. The LPR values and also efficiency calculated by Eq. [3] are presented in Table II. LPR results confirm the inhibitive properties of present terpolymer, as well as the conclusions obtained from potentiodynamic polarization and EIS results.

\section{B. Corrosion Attack Morphology}

\section{Optical microscopy study}

The corrosion attack morphology of the mild steel samples immersed in inhibited and uninhibited (blank) solutions for 90 minutes was studied by optical microscopy, and the metallographic results are presented in Figure 4. As seen in Figure 4, the polished surface of mild steel immersed in blank solution is rough and severely corroded so that several pits are observed dispersed at the surface (Figure 4(a)), while in the case of inhibited solution, less corrosion attack is detected and the specimen surface is nearly unchanged. In the micrograph in Figure 4(b), the pearlite phase is partially etched and the grain boundaries of ferrite phase are not observed.

\section{AFM study}

After immersion for 90 minutes in $1 \mathrm{M} \mathrm{HCl}$ solution with or without $0.8 \mathrm{mmol} / \mathrm{L}$ ATP, the surfaces of mild steel specimens were observed by AFM, and the recorded threedimensional and two-dimensional images of surface topography are shown in Figure 5. Also, the values of surface roughness acquired when analyzing the AFM results are presented in Table III. As can be seen in Table III, in the presence of $0.8 \mathrm{mmol} / \mathrm{L} \mathrm{ATP}$, all roughness parameters have values significantly lower than those of the blank solution. This is an indication of the lower uniform corrosion rate in acidic solution for mild steel in the presence of ATP. For example, the calculated value of the average 

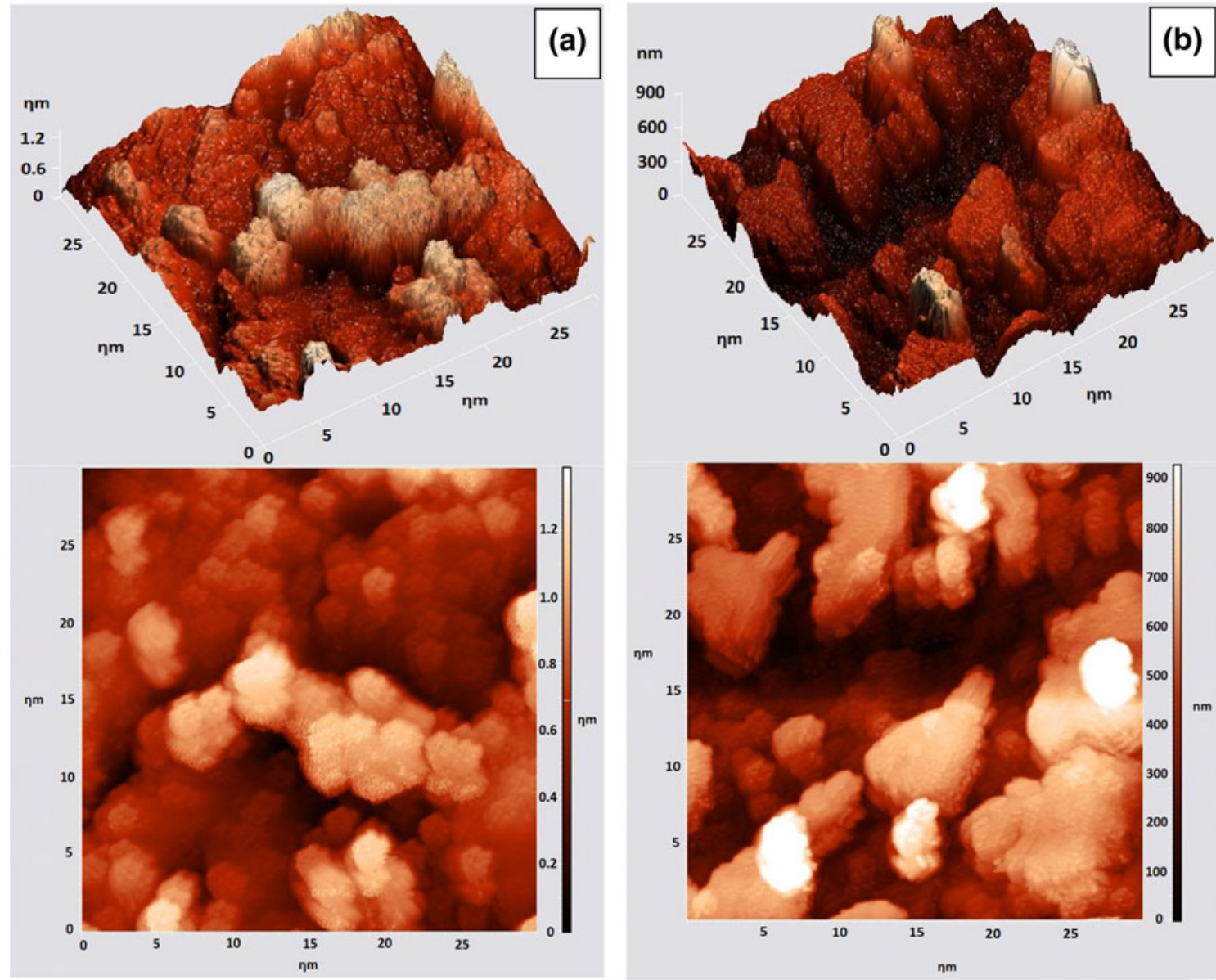

Fig. 5- Corrosion attack morphology obtained by atomic force microscope $(a)$ in blank solution and $(b)$ in the presence of 0.8 ppm ATP.

Table III. Roughness Parameters Extracted from Topography Results Obtained by AFM in the Presence and Absence of ATP

\begin{tabular}{lcccc}
\hline Condition & Peak-to-Peak Value (nm) & Mean Value (nm) & Roughness Average (nm) & Root-Mean-Square (nm) \\
\hline Uninhibited solution & 1383 & 659 & 175 & 220 \\
Inhibited solution & 923 & 297 & 123 & 150 \\
\hline
\end{tabular}

roughness for the sample immersed in blank solution is $175 \mathrm{~nm}$, while this value is $123 \mathrm{~nm}$ for the inhibited one.

Besides, the AFM results confirmed the EIS outcomes (Table II) in which the $n$ value (which is an indication of surface roughness in the CPE-derived parameter) increases from 0.78 to 0.89 by adding $0.8 \mathrm{mmol} / \mathrm{L}$ ATP to $1 \mathrm{M} \mathrm{HCl}$ solution.

\section{Effect of Temperature}

The influence of different temperatures on the mild steel corrosion rate was studied in the absence and presence of $0.8 \mathrm{mmol} / \mathrm{L}$ ATP in $1 \mathrm{M} \mathrm{HCl}$. For this purpose, potentiodynamic polarization was performed at different temperatures from $298 \mathrm{~K}$ to $313 \mathrm{~K}\left(25^{\circ} \mathrm{C}\right.$ to $40{ }^{\circ} \mathrm{C}$ ) in the absence and presence of ATP. The polarization curves and also the extracted electrochemical parameters corresponding to polarization results at various temperatures are presented in Figure 6 and
Table IV, respectively. It is obvious that with rising temperature, the corrosion current density increases in uninhibited and inhibited solutions, while the inhibition efficiency is nearly constant. Thus, it can be claimed that the inhibition efficiency of the present terpolymer is temperature independent in $1 \mathrm{M} \mathrm{HCl}$ in the range of $298 \mathrm{~K}$ to $313 \mathrm{~K}\left(25^{\circ} \mathrm{C}\right.$ to $\left.40{ }^{\circ} \mathrm{C}\right)$.

Valuable information about the adsorption mechanism of the inhibitor can be obtained from the activation energy values. This parameter can be obtained by studying the influence of temperature on corrosion inhibition. In this way, the Arrhenius equation is used in order to calculate the activation energy in inhibited and uninhibited solutions ${ }^{[47-49]}$.

$$
i_{\text {corr }}=\operatorname{Aexp}\left(\frac{-E_{a}}{\mathrm{R} T}\right)
$$

where $A$ is the pre-exponential factor and $E_{a}$ is the activation energy of the corrosion process. Figure 7 


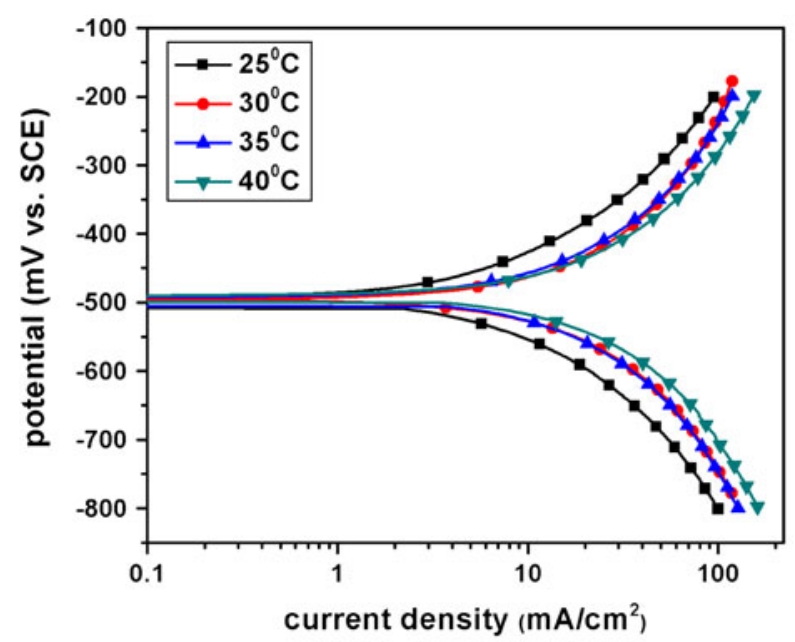

(a)

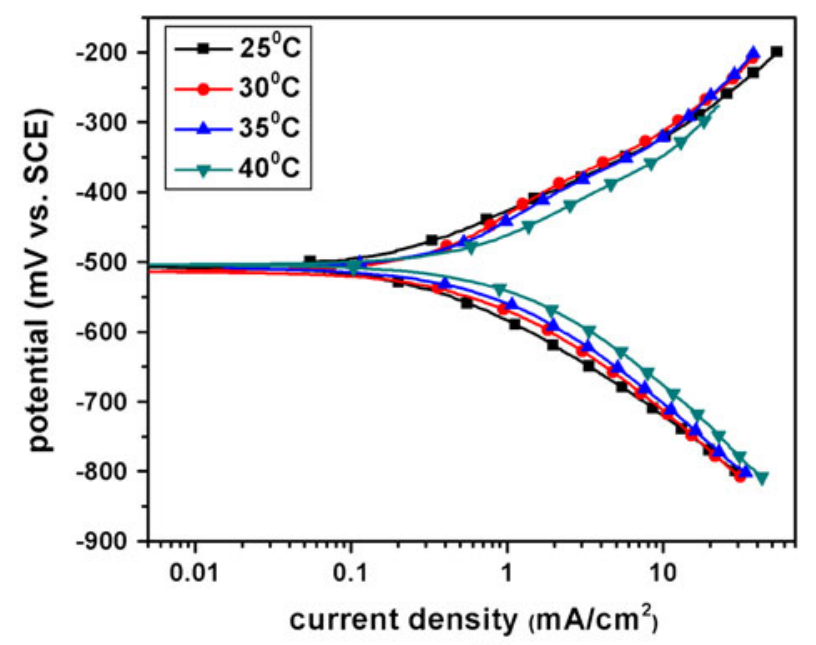

(b)

Fig. 6-Effect of temperature on the potentiodynamic polarization curves of mild steel in $(a)$ uninhibited and $(b)$ inhibited solution with $0.8 \mathrm{mmol} / \mathrm{L} \mathrm{ATP}$.

Table IV. Potentiodynamic Polarization Parameters of Mild Steel in $1 \mathrm{M} \mathrm{HCl}$ Solution in the Presence of $0.8 \mathrm{mmol} / \mathrm{L}$ Concentration of ATP at Different Temperatures

\begin{tabular}{|c|c|c|c|c|c|c|c|}
\hline$T\left({ }^{\circ} \mathrm{C}\right)$ & Solution & $E_{\text {corr }}(\mathrm{mV} v s \mathrm{SCE})$ & $i_{\text {corr }}\left(\mathrm{mA} / \mathrm{cm}^{2}\right)$ & $\beta_{a}(\mathrm{mV} /$ Decade $)$ & $\beta_{c}(\mathrm{mV} /$ Decade $)$ & $\theta$ & $\eta(\mathrm{Pct})$ \\
\hline \multirow[t]{2}{*}{25} & blank & -478 & 1.398 & 240 & 228 & 0.950 & 95.0 \\
\hline & ATP & -500 & 0.071 & 121 & 143 & & \\
\hline \multirow[t]{2}{*}{30} & blank & -501 & 1.462 & 337 & 389 & 0.954 & 95.4 \\
\hline & ATP & -508 & 0.076 & 144 & 146 & & \\
\hline \multirow[t]{2}{*}{35} & blank & -500 & 1.571 & 379 & 419 & 0.958 & 95.8 \\
\hline & ATP & -502 & 0.090 & 127 & 171 & & \\
\hline \multirow[t]{2}{*}{40} & blank & -498 & 1.721 & 420 & 429 & 0.959 & 95.9 \\
\hline & ATP & -508 & 0.116 & 116 & 164 & & \\
\hline
\end{tabular}

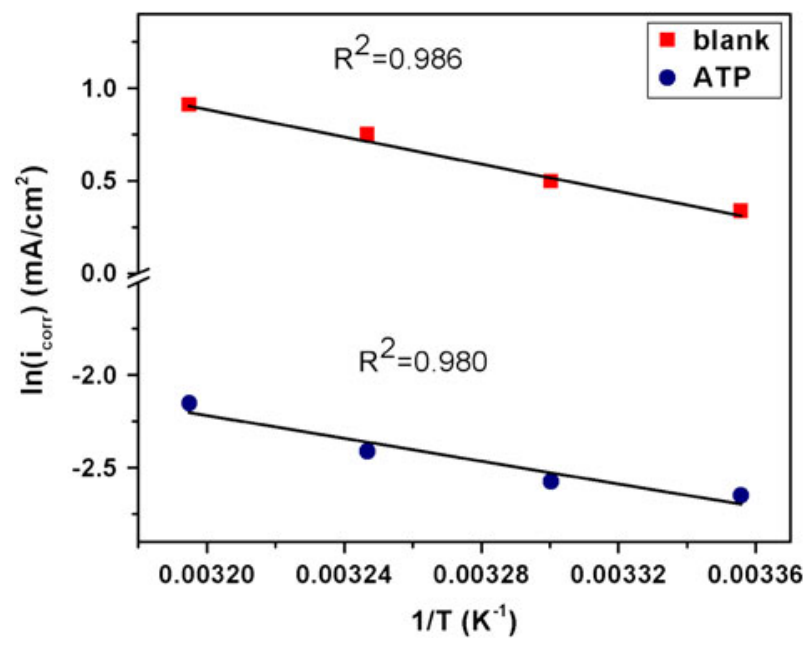

Fig. $7-\ln \left(i_{\text {corr }}\right)$ vs $1 / T$ for mild steel dissolution in $1 \mathrm{M} \mathrm{HCl}$ in the absence and presence of $0.8 \mathrm{mmol} / \mathrm{L}$ inhibitor concentration.

presents the Arrhenius plots of the $\ln \left(i_{\text {corr }}\right)$ vs $1 / T$ in absence and presence of terpolymer in $1 \mathrm{M} \mathrm{HCl}$ and the calculated values of activation energy has been given in Table V. Looking at Table $\mathrm{V}$ shows that the $E_{a}$ value related to $1 \mathrm{M} \mathrm{HCl}$ containing terpolymer has a lower value in comparison with $E_{a}$ value of blank solution. This phenomenon can be interpreted as chemical adsorption (chemisorption) that occurs in the first stage. ${ }^{50]}$ The decrease in activation energy can be attributed to an insignificant increase in the inhibitor desorption from the steel surface with a rise in temperature. $^{[51]}$

\section{Thermodynamic Calculations of Inhibitor Adsorption}

The primary step in the action of inhibitors in acid solutions is adsorption onto the metal surface, which is usually an oxide-free surface. It has been reported that the inhibition mechanism of an inhibitor may vary with factors such as concentration, $\mathrm{pH}$, nature of the anion of the acid, and nature of the metal. ${ }^{[52]}$ Thus, basic information on the interaction between the inhibitor and the mild steel surface can be provided by the adsorption isotherm. In order to obtain the thermodynamic parameters, the relation between surface coverage $(\theta)$ values and inhibitor concentration $(C)$ must be considered. So far, several attempts were made to find the relation between $\theta$ and $C$ such as Langmuir, Temkin, Frumkin, and Flory-Huggins. ${ }^{[53-55]}$ The Langmuir adsorption isotherm was generally found to be the appreciable description of the adsorption behavior of 
Table V. Thermodynamic Parameters Related to the Adsorption of Terpolymer on Mild Steel Surface in the Inhibited and Uninhibited 1 M HCl Solutions

\begin{tabular}{lcccc}
\hline Solution & $\begin{array}{c}E_{a} \\
(\mathrm{~kJ} / \mathrm{mol})\end{array}$ & $\Delta G_{\text {ads }}(\mathrm{kJ} / \mathrm{mol})$ & $\Delta H_{\text {ads }}(\mathrm{kJ} / \mathrm{mol})$ & $\Delta S_{\text {ads }}(\mathrm{J} / \mathrm{mol} \cdot \mathrm{K})$ \\
\hline Blank & 36.95 & $-\overline{-38.74}$ & $\overline{11} .50$ & $-\overline{168}$ \\
ATP & 25.59 & -50 & 168 \\
\hline
\end{tabular}

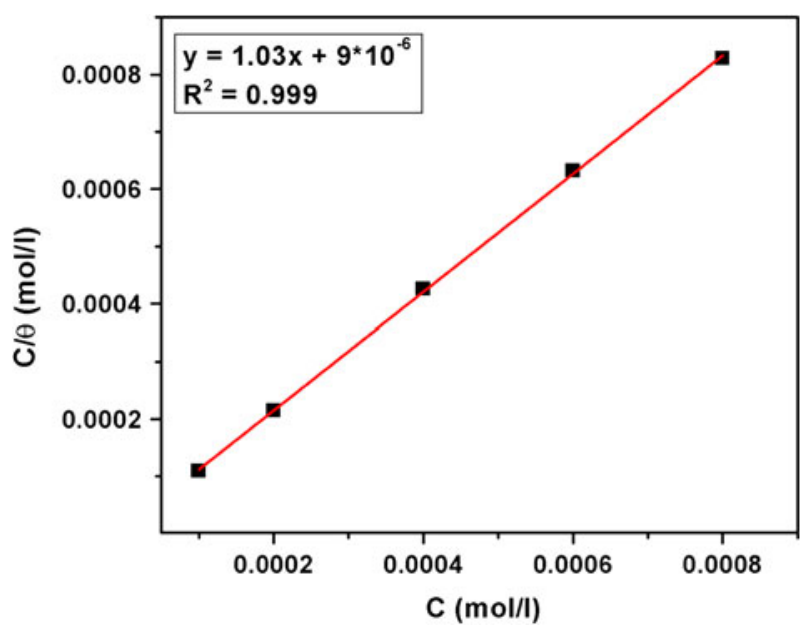

Fig. 8- Langmuir adsorption isotherm of inhibitor in $1 \mathrm{M} \mathrm{HCl}$ at $298 \mathrm{~K}\left(25^{\circ} \mathrm{C}\right)$.

the inhibitor. ${ }^{[47,53,55]}$ According to the Langmuir isotherm, the relation between $\theta$ values and inhibitor concentration, $C$, is considered as follows ${ }^{[47]}$ :

$$
\frac{C}{\theta}=\frac{1}{K_{\mathrm{ads}}}+C
$$

where $K_{\text {ads }}$ is the equilibrium constant of the adsorption process and $C$ is the inhibitor concentration. Figure 8 shows $C / \theta$ variations as a function of $C$. The obtained plot of the inhibitor is perfectly linear with a correlation coefficient higher than 0.999 and it shows that the present terpolymer obeys Langmuir isotherm. The equilibrium constant of adsorption $K_{\text {ads }}$ is related to the standard free energy of adsorption $\left(\Delta G_{\text {ads }}\right)$ with the following equation ${ }^{[35]}$ :

$$
\Delta G_{\mathrm{ads}}^{\circ}=-\mathrm{R} T \ln \left(55.5 K_{\mathrm{ads}}\right)
$$

In this expression, $\mathrm{R}$ is the gas constant, $T$ is the absolute temperature, and 55.5 is the concentration of water in solution in $\mathrm{mol} / \mathrm{L}$. The $\Delta G_{\text {ads }}^{\circ}$ value corresponding to ATP was calculated and is presented in Table V. The negative sign of $\Delta G_{\text {ads }}^{\circ}$ refers to the adsorption of inhibitors onto the metal surface. ${ }^{[56]}$ In general, the magnitude of $\Delta G_{\text {ads }}^{\circ}$ approximately $-20 \mathrm{~kJ} / \mathrm{mol}$ or less negative is assumed for existing electrostatic interactions between the inhibitor and the charged metal surface (i.e., physisorption). Those $\Delta G_{\text {ads }}^{\circ}$ values around $-40 \mathrm{~kJ} / \mathrm{mol}$ or more negative are an indication of charge sharing or charge transferring from an organic specie to the metal surface to form a

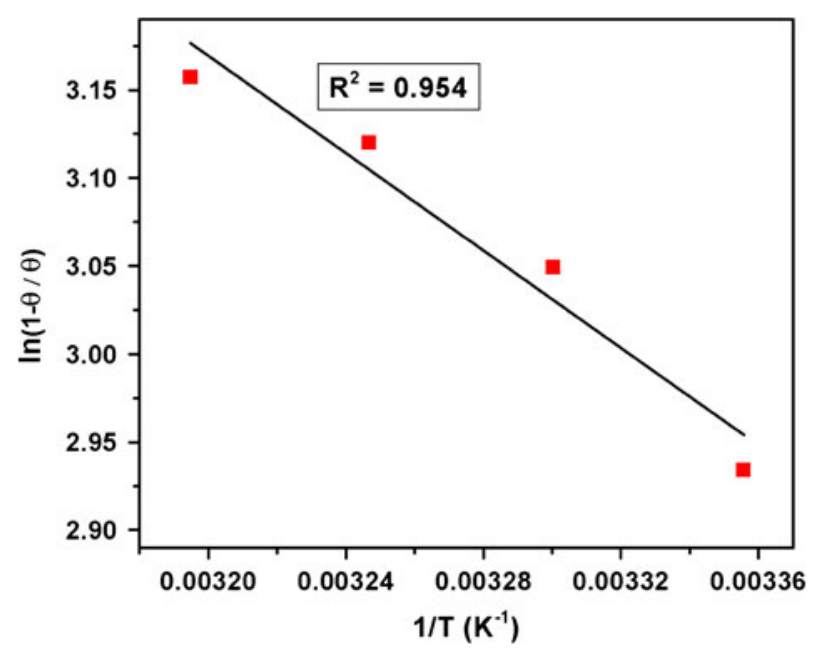

Fig. $9-\ln (1-\theta / \theta)$ vs $1 / T$ for mild steel dissolution in $1 \mathrm{M} \mathrm{HCl}$ in the absence and presence of 0.8 ppm ATP.

coordinate type of metallic bond (i.e., chemisorption). ${ }^{[48]}$ Considering the preceding notifications and the $\Delta G_{\text {ads }}^{\circ}$ value of the present terpolymer $\left(\Delta G_{\mathrm{ads}}^{\circ}=-38.74 \mathrm{~kJ} /\right.$ $\mathrm{mol})$, it can be claimed that ATP has a nearly chemical adsorption onto the mild steel surface. This conclusion was previously acquired by computing $E_{a}$. Moreover, the Gibbs-Helmholtz equation can be used to determine the heat of the adsorption process $\left(\Delta H_{\mathrm{ads}}^{\circ}\right)$. With good estimation, a linear relation between $\ln (\theta / 1-\theta)$ and $1 / T$ is considered as follows ${ }^{[48,56,57]}$.

$$
\ln \left(\frac{\theta}{1-\theta}\right)=\ln (B \cdot C)-\frac{\Delta H_{\mathrm{ads}}^{\circ}}{\mathrm{R} T}
$$

In this expression, $C$ is the inhibitor concentration $(0.8 \mathrm{ppm})$ and $B$ is a constant value. Figure 9 shows an acceptable linear regression $\left(R^{2}=0.954\right)$. In addition, the $\Delta H_{\text {ads }}^{\circ}$ calculated using Eq. [9] is presented in Table V. An endothermic adsorption process $\left(\Delta H_{\text {ads }}^{\circ}>0\right)$ is due to chemisorptions, while an exothermic one $\left(\Delta H_{\mathrm{ads}}^{\circ}<0\right)$ may be attributed to physisorption, chemisorption, or a mixture of both. ${ }^{[47]}$ For physisorption processes, this magnitude is usually lower than $40 \mathrm{~kJ} / \mathrm{mol}$, while it usually is close to $100 \mathrm{~kJ} / \mathrm{mol}$ in chemisorptions. ${ }^{[58]}$ In this work, the $\Delta H_{\text {ads }}^{\circ}$ value indicates the chemical adsorption that is in agreement with the results obtained by the activation parameter $\left(E_{a}\right)$ and $\Delta G_{\text {ads }}^{\circ}$.

Also, for determination of the entropy of the adsorption process $\left(\Delta S_{\mathrm{ads}}^{\circ}\right)$, the following expression is used $^{[35,47,56]}$. 


$$
\Delta G_{\mathrm{ads}}^{\circ}=\Delta H_{\mathrm{ads}}^{\circ}-\Delta S_{\mathrm{ads}}^{\circ}
$$

The positive signs of $\Delta S_{\text {ads }}^{\circ}$ for the inhibitor are related to the substitutional process, which can be attributed to the increase in water desorption entropy. ${ }^{[48,59]}$ It could be interpreted that inhibitor molecules can desorb water molecules from the metal surface, causing an increase in disorders of the system. ${ }^{[47,56]}$ In other words, it can be claimed that the molecule that adsorbs at the surface with better order produces higher protection against corrosion. ${ }^{[60]}$

\section{E. Effect of Immersion Time}

\section{Potentiodynamic polarization}

Immersion times of $1,6,12,18$, and 24 hours were chosen to investigate the effect of time on the inhibitor properties by potentiodynamic polarization in $1 \mathrm{M} \mathrm{HCl}$ containing $0.8 \mathrm{ppm}$ ATP at $298 \mathrm{~K}\left(25^{\circ} \mathrm{C}\right)$ (Figure 10). Electrochemical parameters related to these curves were extracted by Tafel extrapolation and are presented in Table VI. Figure 10 depicts that the polarization of anodic branches can be divided into two parts. The first part has a potential from 0 to $150 \mathrm{mV}$ higher than open circuit potential, and it is considered as a region at which to determine the anodic corrosion current. The current densities of this part diminish with the passing of

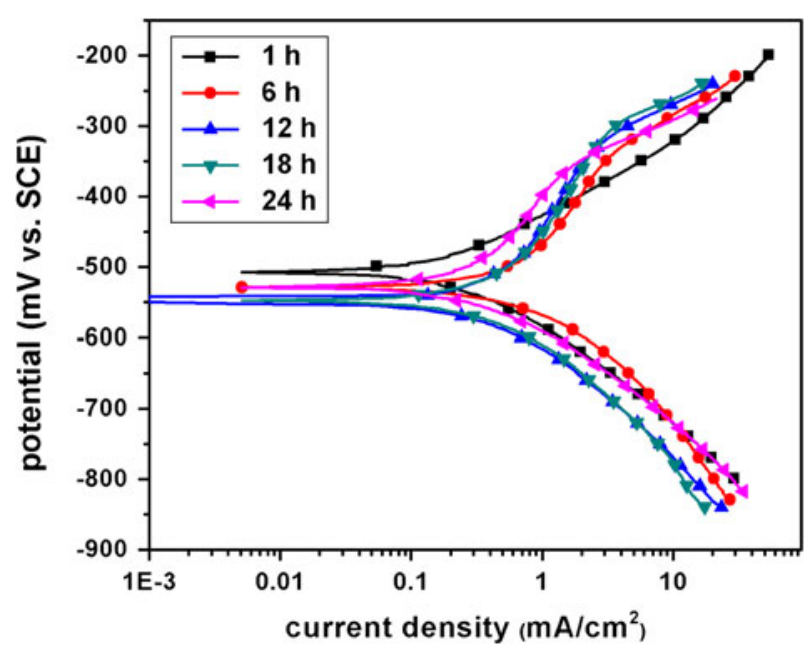

Fig. 10-Effect of immersion time on the potentiodynamic behavior of mild steel in inhibited solution with $0.8 \mathrm{ppm}$ ATP at $298 \mathrm{~K}$ $\left(25^{\circ} \mathrm{C}\right)$. time. The reason for a rise in corrosion resistance can be associated with more substitution of inhibitor molecules with water molecules at the metal surface. Second, with more anodic polarization, the Tafel slopes abruptly change and current densities increase. This phenomenon can be related to the terpolymer desorption from sites where inhibitors have a weak electrostatic interaction with the metal surface. ${ }^{[61]}$ In addition, a decrease in cathodic branches is observed as time elapses. In contrast with inhibited solution, an increase in corrosion current density of mild steel with time passage is observed in $1 \mathrm{M} \mathrm{HCl}$ solution. The reason for this observation can be related to an increase in metal surface area due to excess dissolution of iron. ${ }^{[62]} \mathrm{In}$ summary, with elapsing time, a considerable decrease in corrosion current density in the presence of an inhibitor can be observed and the efficiency of inhibitors increases, as shown in Table VI.

\section{Electrochemical impedance spectroscopy}

Electrochemical impedance spectroscopy is a useful technique for long time investigation, because it does not significantly disturb the system and it is possible to follow system behavior over time. ${ }^{[24]}$ Figure 11 represents the variation of Nyquist plots with the immersion time recorded for terpolymer. The results showed that the immersion time has a great influence on the size of the impedance spectra and, therefore, the inhibitive behavior of the present terpolymer. The depressed semicircle was found to increase in size with the increase in immersion time, reaching a maximum in 24 hours. Also, electrochemical parameters extracted from EIS measurement (Table VII) show that the $R_{c t}$ values increased from $94 \Omega \cdot \mathrm{cm}^{2}$ at 1 hour to $144.6 \Omega \cdot \mathrm{cm}^{2}$ at 24 hours. No change is observed in type of Nyquist plots (equivalent circuit) with the increase in immersion time, and they consist of a depressed semicircle. This behavior can be related to greater adsorption of the inhibitor molecular at the surface, resulting in a decrease in active area. With elapsing time, terpolymer molecules adsorb at the surface or agglomerate around the surface in a manner in which they create no other inhibitive layer. ${ }^{[17]}$ Thus, the charge transfer resistance only appears in the Nyquist plot. These results demonstrate that a rise in immersion time has a positive effect on inhibition efficiency and corrosion resistance increases with elapsing time in inhibited solution.

\section{F. Effect of Structure}

The first estimate of the ability of the inhibitive behavior of a compound is to act as an electron donor. Organic compounds are protonated in acidic solutions,

Table VI. Potentiodynamic Polarization Parameters of Mild Steel in 1 M HCl Solution in the Presence of 0.8 mmol/L ATP at $298 \mathrm{~K}\left(25^{\circ} \mathrm{C}\right)$ in Varoius Immersion Times

\begin{tabular}{lcccc}
\hline Time $(\mathrm{h})$ & $E_{\text {corr }}(\mathrm{mV}$ vs SCE $)$ & $i_{\text {corr }}\left(\mathrm{mA} / \mathrm{cm}^{2}\right)$ & $\beta_{a}(\mathrm{mV} /$ Decade $)$ & $\beta_{c}(\mathrm{mV} /$ Decade $)$ \\
\hline 1 & -500 & 0.071 & 121 & 143 \\
6 & -529 & 0.066 & 113 & 141 \\
12 & -540 & 0.056 & 106 & 139 \\
18 & -421 & 0.050 & 94 & 135 \\
24 & -517 & 0.036 & 73 & 119 \\
\hline
\end{tabular}




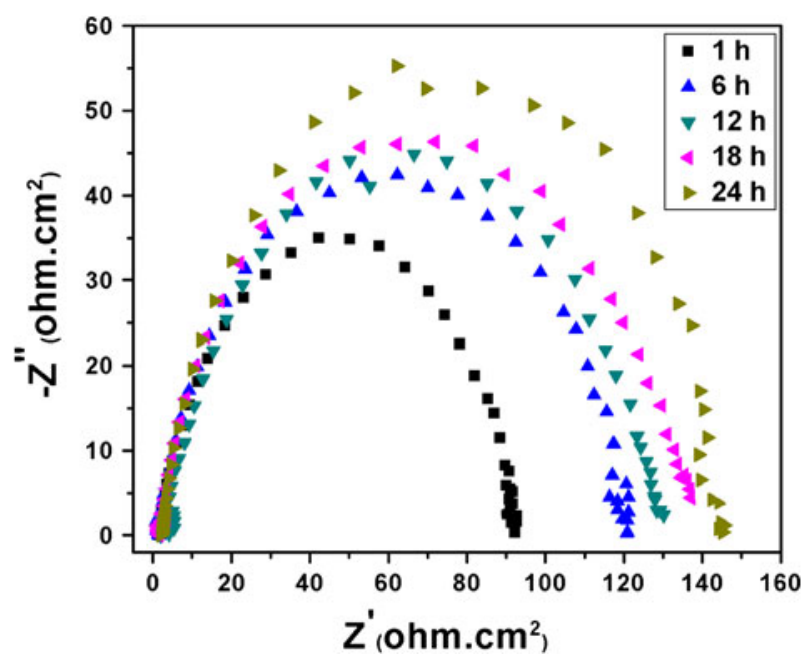

Fig. 11-Effect of time on Nyquist plot of mild steel in inhibited solutions in concentration of $0.8 \mathrm{mmol} / \mathrm{L}$ at $298 \mathrm{~K}\left(25^{\circ} \mathrm{C}\right)$.

Table VII. Electrochemical Impedance Spectroscopy Parameters of Mild Steel Obtained from EIS Results in Different Immersion Times in Inhibited Solution at $298 \mathrm{~K}\left(25^{\circ} \mathrm{C}\right)$

\begin{tabular}{lcccc}
\hline Time $(\mathrm{h})$ & $R_{c t}\left(\Omega \cdot \mathrm{cm}^{2}\right)$ & $P\left(\mu \mathrm{F} / \mathrm{cm}^{2}\right)$ & $n$ & $C_{d l}\left(\mu \mathrm{F} \cdot \mathrm{cm}^{2}\right)$ \\
\hline 1 & 91.0 & 103 & 0.89 & 56.1 \\
6 & 121.7 & 260 & 0.78 & 96.6 \\
12 & 127.5 & 290 & 0.78 & 111.4 \\
18 & 136.2 & 220 & 0.77 & 80.3 \\
24 & 144.6 & 180 & 0.83 & 83.8 \\
\hline
\end{tabular}

but as one molecule approaches the metal surface, it loses its proton so that the lone pair of electrons on the heteroatoms can interact with the metal surface. In order to determine this effect, the quantum chemical study method was employed and the results are presented in Figure 12. The HOMO of monomers of the present terpolymer optimized by the DFT method using the B3LYP level and 3-21G** basis set with Gaussian 98 reveals that oxygen atoms existing in monomers have a large electron density. Lone pair electrons of oxygen can be suitable sites to adsorb onto the metal surface. It is reported that these electrons are an agent for charge sharing or charge transferring, resulting in chemisorptions. In addition, surface chelates are formed involving bonding between a surface cation and heteroatom atom in the chelating molecule (i.e., chelates between heteroatoms such as oxygen, sulfur, nitrogen, and metal cations such as $\left.\mathrm{Fe}^{2+}\right) .{ }^{[54,63]}$

A second factor in determining the effectiveness of a chemisorbed organic inhibitor is the molecular size. In general, the molecules having a larger area create the better inhibitive behavior. However, with very large molecules (such as polymers), there may be steric hindrance problems when a large molecule attempts to fit onto a surface already partially occupied with previously adsorbed molecules. Thus, complete coverage of the surface by large molecules may sometimes be difficult to achieve. ${ }^{[64]}$ In this study, in inhibited solution, competitive adsorption is assumed to occur at a low carbon steel surface between the aggressive $\mathrm{Cl}^{-}$ions and the inhibitor molecules. As known, the predominant
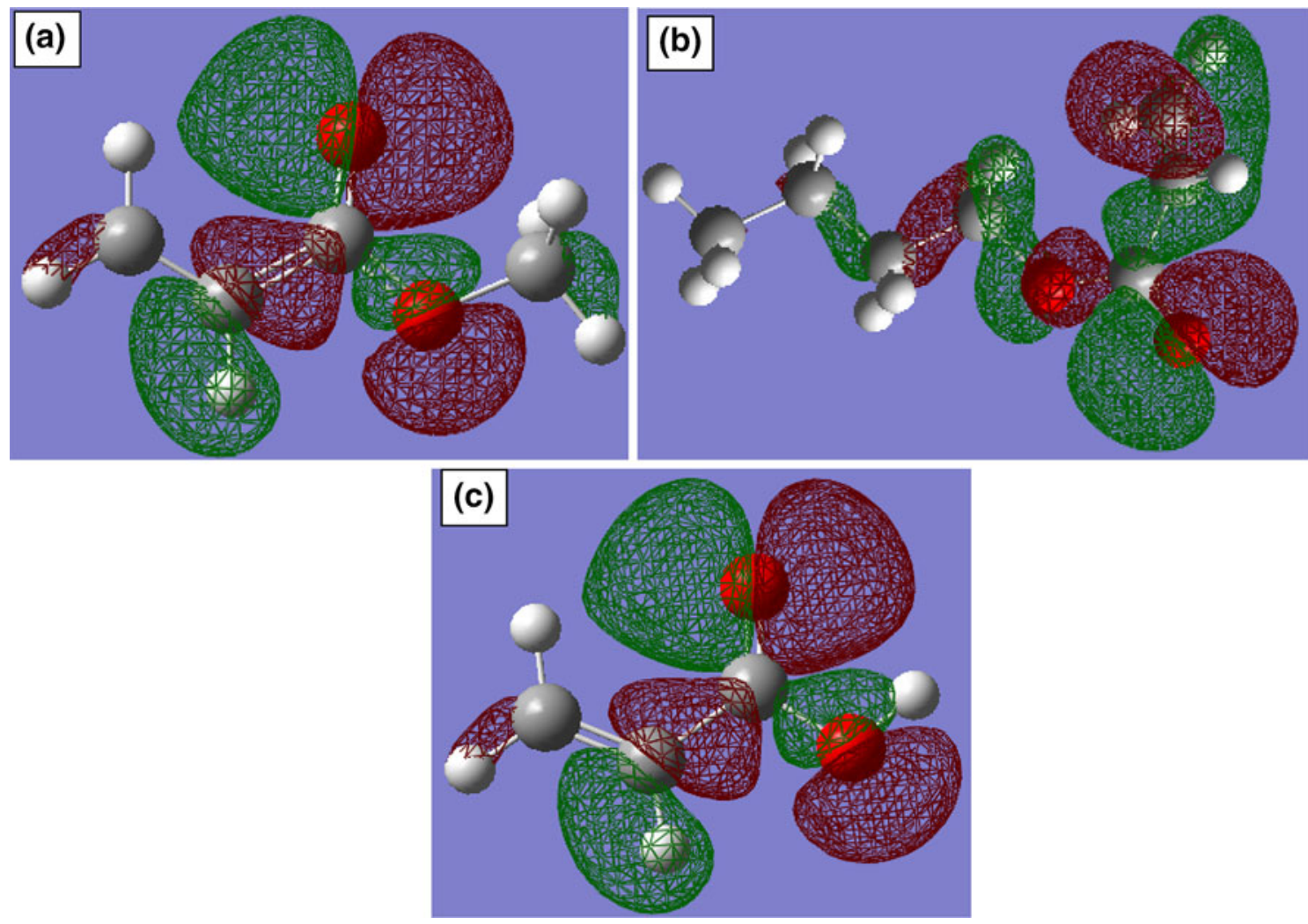

Fig. 12-Molecular structure and HOMO of (a) methyl meta acrylate, (b) butyl acrylate, and (c) acrylic acid. 
reason for corrosion process of mild steel in $\mathrm{HCl}$ solution is the adsorption of $\mathrm{Cl}^{-}$ions onto its bare metallic surface sites. The mobility of $\mathrm{Cl}^{-}$is higher than terpolymer; therefore, the long chains cannot compete with $\mathrm{Cl}^{-}$ions, but terpolymer adsorption can prevent $\mathrm{Cl}^{-}$ions from reaching the steel surface sites by steric effect. Also, in relation to corrosion inhibition, when an inhibited solution contains adsorbable anions, such as halide ions, these adsorb on the metal surface by creating oriented dipoles and, consequently, increase the adsorption of the organic cations on the dipoles. In these cases, a positive synergistic effect arises; therefore, the degree of inhibition in the presence of both adsorbable anions and inhibitor cations is higher than the sum of the individual effects. ${ }^{[65]}$ This could explain the higher inhibition efficiency of various organic inhibitors in hydrochloric acid solutions compared to sulfuric acid solutions. In this work, in order to examine this phenomenon, several electrochemical tests including potentiodynamic polarization and EIS measurement were carried out in $\mathrm{H}_{2} \mathrm{SO}_{4}$ media (the results were not shown here). It was observed that the inhibitor efficiency of the present terpolymer unexceptionally decreases and approaches values of 40 pct.

The third factor affecting chemisorption, and thus inhibition, is the solubility of the organic soluble molecule. Less soluble molecules have a greater tendency to be adsorbed and have more stability than soluble molecules. $^{[44,45]}$ Because ATP is an emulsion polymer, it contains polymer particles in colloidal form, which are not soluble, so it has greater stability and better inhibitive behavior than completely soluble polymers.

\section{CONCLUSIONS}

1. Addition of the ATP to the acidic solution inhibits the corrosion of mild steel. The inhibition is due to the adsorption of this compound on the surface of mild steel.

2. Polarization measurements showed that the ATP functions as a mixed-type inhibitor.

3. EIS measurements recorded for mild steel in the 1 $\mathrm{M} \mathrm{HCl}$ solution in the absence and presence of the ATP inhibitors showed that the Nyquist diagrams consist of a large capacitive loop, which determines that the ATP increases the charge transfer resistance of the double layer on the surface.

4. The inhibition efficiencies of ATP increased with increasing its concentration and the immersion time.

5. Adsorption on the present inhibitor obeys the Langmuir isotherm, and the thermodynamic data extracted by this isotherm show the chemisorption process.

6. In all cases, the negative sign of the $\Delta G_{\text {ads }}^{\circ}$ and $\Delta H_{\text {ads }}^{\circ}$ indicates that the adsorption process is spontaneous and endothermic. The value of $\Delta G_{\text {ads }}^{\circ}$ is $40 \mathrm{~kJ} \mathrm{~mol}^{-1}$, which may result from the electrostatic interactions of multireaction centers of the polymer with the charged Fe surface, especially at higher concentrations of terpolymer.
7. AFM and OM examinations also demonstrate a decrease in surface roughness and corrosion attacks, respectively, in the presence of ATP, in good agreement with EIS results.

8. Quantum chemical study reveals that lone pair electrons of oxygen can be suitable sites to adsorb onto the metal surface.

\section{ACKNOWLEDGMENT}

The authors acknowledge Hakim Sabzevari University for financial support and the provision of facilities to perform the experiments.

\section{REFERENCES}

1. S.A. Ali, M.T. Saeed, and S.U. Rahman: Corros. Sci., 2003, vol. 45 , pp. $253-66$

2. A. Kosari, M. Momeni, R. Parvizi, M. Zakeri, M.H. Moayed, A. Davoodi, and H. Eshghi: Corros. Sci., 2011, vol. 53, pp. 3058-67.

3. M. Lagrenée, B. Mernari, M. Bouanis, M. Traisnel, and F. Bentiss: Corros. Sci., 2002, vol. 44, pp. 573-88.

4. M.A. Quraishi, F.A. Ansari, and D. Jamal: Mater. Chem. Phys., 2003, vol. 77, pp. 687-90.

5. M.A. Quraishi and R. Sardar: Mater. Chem. Phys., 2003, vol. 78, pp. 425-31.

6. M.A. Quraishi and S.K. Shukla: Mater. Chem. Phys., 2009, vol. 113, pp. 685-89.

7. M. Vakili Azghandi, A. Davoodi, G.A. Farzi, and A. Kosari: Corros. Sci., 2012, vol. 64, pp. 44-54.

8. B.C. Edwards: Corros. Sci., 1969, vol. 9, pp. 395-404

9. R. Karthikaiselvi and S. Subhashini: Arab. J. Chem., 2012, vol. 6, pp. 424-29.

10. S.K. Shukla, M.A. Quraishi, and R. Prakash: Corros. Sci., 2008, vol. 50, pp. 2867-72.

11. M. Srimathi, R. Rajalakshmi, and S. Subhashini: Arab. J. Chem., 2012, vol. 5, pp. 517-22.

12. S. Muralidharan, M.A. Quraishi, and V.K. Iyer: Corros. Sci., 1995, vol. 37, pp. 1739-50.

13. S.A. Umoren: Pigm. Resin Technol., 2008, vol. 15, pp. 277-86.

14. R.R. Annand and R.M. Hurd: Electrochem. Soc., 1965, vol. 112, pp. 138-44.

15. S.A. Ali and M.T. Saeed: Polymer, 2001, vol. 42, pp. 2785-94.

16. S.A. Umoren: Open Corros. J, 2009, vol. 13, pp. 175-88.

17. H. Ashassi-Sorkhabi, N. Ghalebsaz-Jeddi, F. Hashemzadeh, and H. Jahani: Electrochim. Acta, 2006, vol. 51, pp. 3848-54.

18. T. Grchev, M. Cvetkovska, and J.W. Schultze: Corros. Sci., 1991, vol. 32, pp. 103-112.

19. Y. Jianguo, W. Lin, V. Otieno-Alego, and D.P. Schweinsberg: Corros. Sci., 1995, vol. 37, pp. 975-85.

20. K.S. Khairouand and A. El-Sayed: Appl. Polym. Sci., 2003, vol. 88 , pp. $866-71$

21. S. Sathiyanarayanan, K. Balakrishnan, S.K. Dhawan, and D.C. Trivedi: Electrochim. Acta, 1994, vol. 39, pp. 831-37.

22. A.Y. El-etre: Corros. Sci., 1998, vol. 40, pp. 1845-50.

23. A. El-Sayed: Corros. Prevent. Contr., 1996, vol. 43, pp. 27-34.

24. G. Moretti, F. Guidi, and G. Grion: Corros. Sci., 2004, vol. 46, pp. 387-403.

25. R.M. Saleh, A.A. Ismail, and A.A. El Hosary: Br. Corros., 1982, vol. 17 , pp. $131-35$

26. L. Qie and M.A. Dubé: Int. J. Adhes. Adhes., 2010, vol. 30, pp. 654-64.

27. K.S.C.R. dos Santos, J.F.J. Coelho, P. Ferreira, I. Pinto, S.G. Lorenzetti, E.I. Ferreira, O.Z. Higa, and M.H. Gil: Int. J. Pharm., 2006, vol. 310, pp. 37-45.

28. P. Shakkthivel and T. Vasudevan: Desalination, 2006, vol. 197, pp. 179-89. 
29. B. Sanyal: Progr. Org. Coat., 1981, vol. 9, pp. 165-236.

30. B. Müller, I. Förster, and W. Kläger: Progr. Org. Coat., 1997, vol. 31, pp. 229-233.

31. M.P. Oliveira, D.S. Giordani, and A.M. Santos: Eur. Polym. J., 2006, vol. 42, pp. 1196-1205.

32. L. Xianghong and M. Guannan: Appl. Surf. Sci., 2005, vol. 252, pp. 1254-65.

33. Q. Qu, L. Li, W. Bai, S. Jiang, and Z. Ding: Corros. Sci., 2009, vol. 51, pp. 2423-28.

34. B. Hirschorn, M.E. Orazem, B. Tribollet, V. Vivier, I. Frateur, and M. Musiani: Electrochim. Acta, 2010, vol. 55, pp. 6218-27.

35. K.F. Khaled and M.M. Al-Qahtani: Mater. Chem. Phys., 2009, vol. 113, pp. 150-58.

36. E.A. Noor: Mater. Chem. Phys., 2009, vol. 114, pp. 533-41.

37. E. McCafferty and N. Hackerman: Electrochem. Soc., 1972 , vol. 119, pp. 146-54.

38. D.A. López, S.N. Simison, and S.R. de Sánchez: Electrochim. Acta, 2003, vol. 48, pp. 845-54.

39. M. Keddam, O. Rosa Mottos, and H. Takenouti: Electrochem. Soc., 1981, vol. 128, pp. 257-66.

40. K.F. Khaled, K. Babic-Samardzija, and N. Hackerman: Corros. Sci., 2006, vol. 48, pp. 3014-34.

41. W.J. Lorenz and F. Mansfeld: Corros. Sci., 1981, vol. 21, pp. $647-$ 72

42. J.R. Macdonald: J. Electroanal. Chem., 1987, vol. 221, pp. 25-50.

43. O. Olivares-Xometl, N.V. Likhanova, M.A. Domínguez-Aguilar, E. Arce, H. Dorantes, and P. Arellanes-Lozada: Mater. Chem. Phys., 2008, vol. 110, pp. 344-51.

44. H. Hamdy: Electrochim. Acta, 2006, vol. 51, pp. 5966-72.

45. A.K. Singh and M.A. Quraishi: Corros. Sci., 2010, vol. 52, pp. 152-60.

46. F. Bentiss, M. Traisnel, and M. Lagrenée: Corros. Sci., 2000, vol. 42 , pp. $127-46$.
47. F. Bentiss, M. Lebrini, and M. Lagrenée: Corros. Sci., 2005, vol. 47, pp. 2915-31.

48. R. Solmaz, G. Kardaş, M. Çulha, B. Yazıcı, and M. Erbil: Electrochim. Acta, 2008, vol. 53, pp. 5941-52.

49. H.L. Wang, H.B. Fan, and J.S. Zheng: Mater. Chem. Phys., 2003, vol. 77, pp. 655-61.

50. M. Behpour, S.M. Ghoreishi, N. Soltani, and M. Salavati-Niasari: Corros. Sci., 2009, vol. 51, pp. 1073-82.

51. T. Szauer and A. Brandt: Electrochim. Acta, 1981, vol. 26, pp. 1253-56.

52. H.D. Leçe, K.C. Emregül, and O. Atakol: Corros. Sci., 2008, vol. 50, pp. 1460-68.

53. L.M. Vracar and D.M. Drazic: Corros. Sci., 2002, vol. 44, pp. $1669-80$.

54. L. Herrag, B. Hammouti, S. Elkadiri, A. Aouniti, C. Jama, H. Vezin, and F. Bentiss: Corros. Sci., 2010, vol. 52, pp. 3042-51.

55. E. McCafferty: Introduction to Corrosion Science, Springer Science, New York, NY, 2010.

56. G. Avci: Coll. Surf. A, 2008, vol. 3317, pp. 730-36.

57. S.M.A. Hosseini and A. Azimi: Corros. Sci., 2009, vol. 51, pp. 728-32.

58. E.A. Noor and A.H. Al-Moubaraki: Mater. Chem. Phys., 2008, vol. 110, pp. 145-54.

59. X. Li, S. Deng, H. Fu, and G. Mu: Corros. Sci., 2009, vol. 51, pp. 620-34.

60. J. Aljourani, K. Raeissi, and M.A. Golozar: Corros. Sci., 2009, vol. 51, pp. 1836-43.

61. A.A. Aksüt, W.J. Lorenz, and F. Mansfeld: Corros. Sci., 1982, vol. 22, pp. 611-19.

62. A.K. Satapathy, G. Gunasekaran, S.C. Sahoo, K. Amit, and P.V. Rodrigues: Corros. Sci., 2009, vol. 51, pp. 2848-56.

63. G. Gökhan: Corros. Sci., 2008, vol. 50, pp. 2981-92.

64. S. Rajendran, S.P. Sridevi, N. Anthony, A. John Amalraj, and M. Sundearavadivelu: Anti-Corros. Method M, 2005, vol. 52, pp. 102-09.

65. E.E. Oguzie: Mater. Chem. Phys., 2004, vol. 87, pp. 212-17. 